\title{
Formação Docente e o Suporte da Ferramenta Google Sala de Aula: uma Análise Sob a Perspectiva da Didática Profissional
}

\section{Teacher Training and the Support of the Google Classroom tool: an Analysis from the Perspective of Professional Didactics}

\author{
Francisca Narla Matias Mororóa; Francisco Régis Vieira Alves ${ }^{\mathrm{a}}$; Francisca Claúdia Fernandes Fontenele; \\ Daniel Brandão Menezes*c
}

\author{
anstituto Federal de Educação, Ciência e Tecnologia do Estado do Ceará. CE, Brasil. \\ 'Universidade Estadual Vale do Acaraú. CE, Brasil. \\ 'Universidade Estadual Vale do Acaraú. CE, Brasil. \\ *E-mail: brandaomenezes@hotmail.com
}

\begin{abstract}
Resumo
A formação do professor, em especial para o docente de componentes curriculares específicos, deve privilegiar além de aspectos pedagógicos, questões relacionadas ao desenvolvimento da investigação, da argumentação e do pensamento lógico-crítico. A maneira com que o docente lida com a produção de conhecimento relaciona-se diretamente com o exercício de suas atividades laborais. A vertente francesa de Didática Profissional de modo singular preocupa-se com essa questão. Mas, tendo o ensino o propósito de oferecer suporte para o desenvolvimento pleno aos estudantes, é notório que deve atentar-se para inserção das tecnologias no contexto educacional. E nesse viés, a promoção de ciclos de formação docente que proporcionem a vivência de ferramentas digitais se faz necessário. O objetivo do presente estudo é investigar de que forma a utilização de ferramentas digitais, em especial o Google Sala de Aula, pode contribuir com a realização de formação docente, sob o olhar da Didática Profissional. Para realização desse estudo, utilizou-se uma pesquisa de levantamento de cunho descritivo, a partir de uma coleta de impressões com docentes de Matemática. Analisando e refletindo sobre as concepções da Didática Profissional, da formação do professor e o uso das Tecnologias Digitais de Comunicação e informação na educação, percebe-se que ainda há necessidade de consideráveis estudos e consequentemente melhorias no que compete a formação do professor e ao uso de TDCI's no ensino.
\end{abstract}

Palavras-chave: Didática Profissional. Formação Docente. Tecnologias da Comunicação e Informação.

\begin{abstract}
Teacher training, especially for teachers with specific curricular components, should focus on pedagogical aspects, issues related to the development of research, argumentation and logical-critical thinking. The way in which the teacher deals with the production of knowledge is directly related to the exercise of his work activities. The French strand of Professional Didactics is uniquely concerned with this issue. However, with the purpose of teaching to provide support for full development for students, it is clear that attention should be paid to the insertion of technologies in the educational context. And in this bias, the promotion of teacher training cycles that provide the experience of digital tools is necessary. The aim of the present study is to investigate how the use of digital tools, especially the Google Classroom, can contribute to the realization of teacher training, under the perspective of Professional Didactics. To carry out this study, a survey of descriptive nature was used, based on a collection of impressions with teachers of Mathematics. Analyzing and reflecting on the concepts of Professional Didactics, teacher training and the use of Communication and Information Technologies in education, it is clear that there is still a need for considerable studies and consequently improvements in the competence of teacher training and the use of ICT's in teaching.
\end{abstract}

Keywords: Professional Didactics. Teacher Training. Comunication and Information Technologies.

\section{Introdução}

Discussões acerca da importância e da necessidade de aperfeiçoamento da formação do professor já não são recentes. É possível perceber que esse campo tem ganhado muitas contribuições e espaço de significância no cenário educacional brasileiro. No entanto, acompanhar a velocidade das modificações do sistema de ensino e das carências imediatistas de aprendizagem dos estudantes, tem constituído um desafio a ser vencido.

No Brasil, investigações e estudos nesse sentido, constituíram uma vertente denominada de Educação Matemática, associando-se de maneira direta com o que conhecemos como Didática da Matemática (DM). Essas áreas preocupam-se com questões relacionadas ao ensino e a aprendizagem em Matemática.

Generalizando, compreende-se que o objetivo das pesquisas no campo da formação do professor gira em torno da criação, reorganização e/ou seleção de metodologias, ferramentas e objetos de ensino e de aprendizagem que possibilitem ao professor uma gama de opções que favoreçam seu planejamento e posteriormente, sua efetiva aplicação em ambiente de sala de aula (Sousa, Alves \& Fontenele, 2020).

Sob o olhar de variadas concepções metodológicas, é comum perceber a premissa de que o professor não pode e nem deve estar no centro de processo de ensino e de aprendizagem. Nessa óptica, o docente deve ser um mediador, um influenciador, ou seja, oferecer suporte e estímulo para que os estudantes busquem seu conhecimento, 
sejam investigativos, críticos e capazes de resolver situações desafiadoras e inusitadas, selecionando conhecimentos já adquiridos para tal.

A partir dessas reflexões é possível questionar-se sobre até que ponto os professores em atuação estão preparados para desempenharem o papel que é esperado deles, frente a essas novas concepções de ensino, e do sistema escolar como um todo.

Nesse sentido, a formação docente, em especial para o ensino da matemática, além das questões pedagógicas, deve privilegiar aspectos da construção do pensamento lógico-matemático e o desenvolvimento de habilidades de argumentação, interpretação, compreensão, criação e contextualização dos saberes sistêmicos à realidade dos sujeitos (Morin, 2003).

Compreende-se, portanto, que desde sua formação inicial, o professor deve ser orientado e estimulado a questionar, investigar e somente a partir daí internalizar conhecimentos.

$\mathrm{O}$ docente precisa ter propriedade e segurança no que diz respeito a sua própria aprendizagem. Desse modo, é perceptível que entender como o professor aprende e como se dar essa aprendizagem no ato da sua práxis, deve constituir também um importante eixo para investigação, pesquisas e desenvolvimento de formações pedagógicas.

Apresenta-se então, a Didática Profissional, que surgiu da necessidade de compreender como o adulto desenvolve sua aprendizagem, incluindo também os docentes, e considerando o seu lócus de atuação como participante desse processo contínuo de aperfeiçoamento profissional (Alves \& Jucá, 2019).

Hoje, além de maiores condições físicas e suporte pedagógico para a formação do professor, conta-se com inúmeras ferramentas e plataformas digitais que podem favorecer o contato do docente com o conhecimento ou a reconstrução/adaptação de aprendizagens já internalizadas.

A partir de então, faz-se refletir: que contribuições à utilização de ferramentas digitais, especialmente o Google Sala de Aula, pode oferecer para a realização de formação docente, considerando o viés da Didática Profissional e a opinião de docentes de matemática, atuantes dos anos finais do ensino fundamental?

Em vista disso, o objetivo do presente estudo é investigar de que forma a utilização de ferramentas digitais, em especial o Google Sala de Aula, pode contribuir com a realização de formação docente, sob o olhar da Didática Profissional, considerando a opinião de docentes do componente curricular matemática, atuantes nos anos finais do ensino fundamental.

Nesse estudo traremos em um tópico, conceitos e reflexões acerca da vertente francesa de Didática Profissional. Posteriormente, serão discutidos desafios e necessidades relacionadas com a formação do professor, e em um tópico subsequente, elucidar as contribuições do uso das TDCI's (Tecnologia Digitais de comunicação e informação) no contexto do ensino.

\section{Didática Profissional (DP)}

A Didática Profissional (DP) é uma vertente francesa, originada na década de 1990, influenciada por algumas teorias de aprendizagem e desenvolvimento cognitivo, em especial a Psicologia educacional, a Ergonomia cognitiva e as Didáticas das disciplinas.

De acordo com Pastré, Mayen \& Vergnaud (2006, apud Alves, 2020)

Para um certo número dos seus criadores, a Didática Profissional é originada no contexto e prolongamento da formação de adultos. Uma das formas que aparecem neste momento e que pode ser considerada como uma invenção mais característica da formação profissional contínua (FPC) é a Engenharia de Formação. É um campo de práticas que consiste na construção de dispositivos de formação correspondentes ao conjunto de necessidades identificadas para um determinado público no quadro do seu contexto de trabalho. A formação escolar possui a tendência em descontextualizar a aprendizagem. A Engenharia de Formação vai insistir no contrário, sobre o contexto social no qual irá se efetuar uma aprendizagem de adultos em formação (Pastré, Mayen \& Vergnaud, 2006, apud Alves, 2020).

Para os autores supracitados, a Engenharia Didática de Formação também constitui uma forte influência para a Didática Profissional. Por assim dizer, compreende-se que a DP é composta, de fato, por três vertentes teóricas e uma prática, sendo a Engenharia Didática de Formação (EDF) esta última.

Considerando esse momento inicial, embasado na pesquisa e nos estudos franceses, a DP sofreu evoluções e adaptações, partindo do pressuposto de entender o processo de formação profissional e desenvolvimento dos adultos, compreendendo a influência do ambiente de atuação e formativo, sendo a execução de tarefas próprias de cada função, parte desse processo de investigação, que de maneira geral, se direcionam para problemas de cunho investigativo-representativos (Mendes, Alves \& Santos, 2020).

Assim, o surgimento da Didática Profissional deve-se à necessidade de compreender e desenvolver a aprendizagem profissional de adultos envolvidos em um ambiente de formação e de trabalho, como forma de fortalecimento das características da profissão, em especial à docente, e compreender seu papel social (Alves \& Jucá, 2019).

Desse modo, Pastré (2011, apud Alves, 2020), acredita que a Didática Profissional considera as aprendizagens intrínsecas ao desempenho das atividades profissionais e dos processos formativos envolvidos nas habilidades e competências profissionais desenvolvidas e exigidas pelas atividades laborais. $\mathrm{O}$ autor faz uma afirmativa nesse sentido

A Didática Profissional se centra na aprendizagem das atividades (tarefas). A Didática Profissional pode se qualificar ainda pelo interesse pelo desenvolvimento dos adultos, agregado com a forte ideia de que os adultos encontram desenvolvimento no trabalho (Pastré, 2011, apud Alves, 2020). 
Partindo das concepções acerca das aprendizagens humanas, e direcionando esse olhar para a educação, o papel da DP é analisar teórica e epistemologicamente o desenvolvimento de competências profissionais, relacionando com as perspectivas de trabalho e visando a construção/ reorganização de objetos de aprendizagem. Corroborando com o que afirma Pastré (2002, apud Mendes, Alves \& Santos, 2020), quando diz que não é possível um profissional formarse integralmente sem a análise do seu trabalho, pois só assim compreende-se como o sujeito trabalhador aprende.

A Didática Profissional considera ainda uma perspectiva de aprendizagem baseada na atuação, pois envolve a interação com o ambiente laboral, compreendendo características próprias do ofício e gradativamente, da construção de um modelo de regulação e posteriormente, de ajustes. Assim, a aprendizagem (competência profissional) pode ser confirmada, questionada ou fortalecida mediante as situações enfrentadas (Alves \& Catarino, 2019).

Aliadas às concepções construtivistas, apresenta-se o desenvolvimento da representação mental, ou seja, a construção de modelos mentais existentes na correlação entre a ação aplicada pelos indivíduos (atuantes e aprendentes) e as interações com o próprio objeto (situação/ambiente). Espera-se que em situações que envolvam a construção desses modelos, o enfrentamento de problemas, dificuldades e análise de erros, se desenvolvam aprendizagens profissionais (Rogalski, 2004, apud Alves 2020).

Nesse ponto é necessário atentar-se de maneira breve ao conceito de competências e habilidades, para que assim se compreenda a Didática Profissional em sua essência.

Considerando o olhar da DP, a noção de competência está relacionada com o desempenho particular do profissional no trabalho e referente ao próprio trabalho, mediante a execução de ação, seja ela de maneira potencial ou real. Essa ação deve ter condição visível e perceptível para assim identificar-se como competência profissional (Alves \& Jucá, 2019).

Ressalta-se que nenhuma competência por si só é observável. O que se determina são performances, atitudes e ações derivantes da construção da competência.

Quando se direciona para a competência profissional docente, considera-se ainda a habilidade de lidar com situações inesperadas, situações reais que não estão presentes nas literaturas e documentos normativos dos sistemas de ensino. Colocar-se frente às diferentes situações, como elucidadas anteriormente, também contribui para o desenvolvimento de competências profissionais. Em suma, é característica da Didática Profissional preocupar-se com essas questões (Mayen, 2007, apud Alves \& Jucá, 2019).

Nessa perspectiva, contemplar o modelo de funcionamento dos indivíduos, em especial, no exercício de suas competências profissionais, e os mecanismos envolvidos em sua formação, constituem fundamentos essenciais da Didática Profissional (DP).

Estando ciente de que a Didática Profissional em âmbito educacional relaciona-se com o desenvolvimento e a análise do processo de aprendizagem docente, é simples perceber que a formação docente exerce papel de destaque dentre suas investigações. Por esse motivo, a seguir, discutiremos questões relacionadas à formação docente: importância, desafios e benefícios.

\section{Formação Docente}

Estudos e debates relacionados à necessidade e a importância da realização de formações docentes já se estendem por alguns anos. Reconhece-se que há avanços e transformações que beneficiaram a área. No entanto, ao refletir sobre a efetivação dessas formações, se percebe obstáculos tanto nas práticas pedagógicas, quanto no que concerne à organização dos currículos em matemática (Sousa, Alves \& Fontenele, 2020).

Para Perrenoud (1993) o profissional docente está sentenciado a um constante reconstruir: de seu cotidiano, no que concerne as políticas educacionais, das noções de ética e relacionamento com as pessoas, da epistemologia dos saberes, em um novo jeito de realizar a transposição didática, de contratos pedagógicos e de teorias de aprendizagem.

Fazendo uma análise dessas concepções, compreendese que a formação deve e acontece de forma contínua, seja ela formal, promovida pelos gestores dos sistemas de ensino e federativos, quanto de maneira informalizada, na ação e execução de sua práxis. Essa última, sendo o objeto de estudo e investigação da Didática Profissional (DP).

Imbernón (2010), em sua obra intitulada "Formação continuada de professores", dentre outras características, acredita que a formação continuada docente requisita um clima de confiança e parceria entre os professores, uma organização estável para os cursos de formação, o estímulo e apoio ao processo de formação de maneira livre e democrática, além de adaptação e aceitação do contexto e diversidades vividas por cada docente em específico.

Corroborando com essa ideia, Pastré (2004, apud Alves \& Dias, 2017) compara a formação continuada de professores com o trabalho do engenheiro e a aptidão para a aprendizagem durante toda a vida. Para ele,

A formação contínua tem uma tradição de engenharia de formação que é praticamente tão longa que a sua própria história. Analisar um pedido, analisar necessidades, construir um dispositivo de formação, proceder à sua avaliação: tantas atividades de engenharia que são um pouco as cartas de nobreza da formação profissional contínua. Porque esta é constituída historicamente como um campo de práticas, tratase de práticas analisadas e bem pensadas, que a própria área inventou e codificou (Pastré 2004, apud Alves \& Dias, 2017).

Em consonância com os autores supracitados, compreendese a importância da análise do contexto profissional, as experiências, as adversidades enfrentadas, as oportunidades oferecidas e até mesmo da relação interpessoal com o grupo de profissionais que compartilham da mesma atmosfera de trabalho. 
Fazendo paralelo com essas ideias, Nóvoa (1996) apresenta uma dura reflexão acerca do profissional docente. Reflexão essa que deve ser considerada durante os processos formativos e elaboração de objetos de ensino. Para ele, o professor vive um dilema profissional que se apresenta na forma de duas imagens. A primeira representação diz respeito a um profissional inferior, visto com desconfiança e taxado de detentor de pouca formação. Já no segundo caso, ele é apontado como peça essencial na transformação do ensino e como propulsor de um progresso social e cultural.

Considerando o jovem professor, recentemente formado, é possível enxergar nele as duas situações acima descritas, uma vez que acredita na importância do papel que irá exercer quanto profissional, no entanto, em casos, julga sua formação inicial (cursos de licenciatura, de maneira geral), unicamente suficiente para a realização de sua prática.

Nesse tocante, Mayen, Olry \& Pastré (2017, apud Alves, 2020), apresentam sua concepção acerca de como os professores no início do exercício de sua profissão enxergam os processos formativos e a realidade da práxis. Para eles,

A formação, que conduz a um diploma profissional (mesmo que não seja uma garantia de realizações desejáveis da orientação), aparenta finalizada aos olhos dos jovens adultos, e para eles possui um certo sentido. $\mathrm{O}$ estágio ou o trabalho para o aprendiz são aos próprios olhos finalizados. Finalizados porque eles encontram lugar inicial em uma formação profissional, finalizados, em seguida, pela intenção de aprender para a realização do trabalho, correspondente ao emprego ou ao campo de atuação, finalizados por intermédio de próprios objetivos, com respeito ao local de produção de bens de serviço. [...] na medida em que o trabalho escolar é um trabalho fundamentalmente individual, o trabalho em situação profissional é, primeiramente, realizado por outros. Os resultados são secundariamente para si, posto que são prioritariamente para a estrutura profissional [...] (Mayen, Olry \& Pastré, 2017, apud Alves, 2020).

É necessário difundir a concepção de que o trabalho docente embasado por um forte domínio teórico, em especial para os componentes curriculares específicos, é constantemente construído através do prosseguimento de formação pedagógico-teórica, mas também pelo desenvolvimento e a interação com o trabalho.

Nesse sentindo, não se pode esquecer que o professor atual deve ser um mediador de conhecimentos, um estimulador da pesquisa e da autonomia do aluno em relação a sua aprendizagem. E assim, é possível esperar que o docente também seja responsável por sua autoformação, organização e contextualização do conhecimento, para assim ser capaz de realizar a transposição de saberes.

Por isso, Morin (2003) ressalta que a formação do professor na contemporaneidade deve se preocupar com a curiosidade e o imediatismo dos estudantes. Assim, para ele, uma boa formação é aquela que privilegia a transformação do pensamento do professor e que o auxilie no direcionamento da transposição didática para o atendimento das necessidades dos alunos. Mas para isso, em sua formação o docente precisa ser colocado frente às competências e habilidades que o prepare para sua prática profissional.

No tocante da formação docente, entre outros aspectos, é necessário discutir a relação entre domínio e qualidade dos conhecimentos e das técnicas que constituem o profissional da docência, considerando-se modos de agir, métodos de trabalho, valores individuais e sociais, como fundamentais para a integralização e mobilização de conhecimentos (Sacristán \& Gómes, 2000).

Ademais, não se pode falar dos processos de ensino e de aprendizagem sem destacar a necessidade da inserção cada vez mais efetiva dos recursos e ferramentas tecnológicas de informação e comunicação que estão disponíveis à utilização/ adaptação/reorganização, e que bem usados, apresentando objetivos claros, podem trazer grande enriquecimento ao ensino, de modo particular, da matemática. Nesse sentido, o tópico seguinte apresenta aspectos relacionados à utilização das TDCI's (Tecnologia Digitais de Comunicação e Informação) no contexto do ensino.

\section{Utilização das Tecnologias Digitais de Comunicação e Informação (TDCI's) no Ensino}

A criação e expansão das Tecnologias Digitais de Comunicação e Informação (TDCI's) tem oferecido um leque de possibilidades de inovação a praticamente todas as áreas da sociedade, o que não é diferente com a educação. Estamos inseridos na chamada Cibercultura ${ }^{1}$, período da história caracterizado por proporcionar a disseminação de informações de maneira rápida, por modificar as relações interpessoais, que agora se amplia para uma rede mundial, e por modernizar as maneiras de se comunicar, aprender e ensinar (Araújo \& Araújo, 2013).

Diante dessa condição de revolução social e tecnológica, somos colocados frente a um paradigma: a desmaterialização das ações e funções. As inovações exigem uma série de competências qualificadas para as novas demandas, novos modos de agir, de saber-fazer e de saber ser (Quadro-flores, 2016).

A presença das TDCI's e do dinamismo de reorganização do trabalho também agregou preocupação no campo dos discursos pedagógicos e de formação de professores, partindo do ponto do conhecimento do processo à aplicação em situações reais e concretas. Enfim, nos últimos anos, a utilização das Tecnologias Digitais de Comunicação e Informação tem sido elemento gerador de estudo sobre o ensino e para o ensino (Barreto, 2004).

De maneira ampla, a utilização das Tecnologias Digitais de Comunicação e Informação na educação tem apresentado sentidos diversos, mas em todos os casos, apresenta-se como

1 Cibercultura é definida como "o conjunto de técnicas (materiais e intelectuais), de práticas, de atitudes, de modos de pensamento e de valores que se desenvolvem juntamente com o crescimento do ciberespaço" (Lévi, 1998). 
ponto comum: a vontade de distanciar-se das metodologias retrógradas, geralmente simbolizadas pelo uso exclusivo da tríade: quadro, giz e material impresso.

Atualmente, a gama de possibilidades, ferramentas e recursos digitais que podem ser incorporados ao contexto educacional é bastante ampla, mesmo reconhecendo que nem todos os alunos, professores e escolas tem acesso ou ainda, habilidades formativas suficientes para a utilização e extração completa do que esses recursos podem vir a oferecer se aplicados com coerência e objetivos claros.

Apesar dos desafios, a tecnologia vem se aliando a educação de maneira cada vez mais forte. Assim como afirma Souza, Moita \& Carvalho (2011), quando diz que

Quando as diferentes modalidades expressivas da multimídia são utilizadas de forma integrada pelo professor em seu trabalho pedagógico, estas ações podem favorecer a uma amplitude de possibilidade e sentido para a motivação e aprendizagem do aluno [...] (Souza, Moita \& Carvalho, 2011).

Conforme os autores mencionados, a utilização adequada dos recursos tecnológicos além de agregar motivação e contextualização para o ensino, favorecem a aprendizagem, foco central do trabalho docente.

Dentre os benefícios advindos da popularização das tecnologias aliadas ao campo educacional, é possível destacar a facilidade de produções elaboradas, a construção e distribuição rápida de conteúdo, a quebra de barreiras físicas, a flexibilidade do tempo e espaço, e talvez aquela que seja a de mais importância, a democratização de acesso ao conhecimento e a informação (Almeida, 2003).

No caso específico da Matemática, a utilização de recursos tecnológicos pode favorecer a visualização de aplicações dos conceitos matemáticos com apresentação mais clara e dinâmica (Godino, Batanero \& Font, 2007), como pode-se elucidar no exemplo costumeiro da utilização do software GeoGebra para a construção de representações geométricas de funções.

As instituições e sistemas de ensino tem possibilidade de desenvolverem plataformas digitais que ofereçam suporte pedagógico a estudantes e/ou professores, conforme públicoalvo das mesmas, como forma de complementação de ensino e de formação, que ofereçam flexibilidade de horário, espaço e rotina de estudos.

Há ainda ambientes virtuais de aprendizagem, softwares e plataformas gameficadas já disponíveis na internet, com o objetivo de oferecer suporte para atividades educacionais com a mediação das TDCI's. Essas ferramentas possibilitam a integração de mídias, documentos, e espaço de inteiração entre docentes e discentes, como fóruns e chats, de maneira organizada (Almeida, 2003).

É importante destacar que apesar de considerar a utilização das tecnologias e ferramentas digitais na educação como uma importante aliada na consolidação dos processos de ensino e de aprendizagem, a aplicação delas por si só não é garantia de sucesso. É necessário que o professor tenha objetivos claros quanto à sua utilização e que tenham além das habilidades técnicas, a competência pedagógica de retirar benefícios oferecidos pelas TDCI's.

O profissional precisa ter capacitação adequada para a utilização das Tecnologias Digitais de Comunicação e Informação dentro ou como suporte paralelo à escola. Nesse sentindo, Pereira (2011) afirma que

[...] é necessário rever conceitos e capacitar o profissional de educação, para que este possa não só aprender a manusear o equipamento como também ser capaz de lidar com as informações recebidas e desenvolver o trabalho com os alunos (Pereira, 2011).

Mesmo reconhecendo que ainda existe um desequilíbrio de acesso à tecnologia quando comparada a educação básica pública e privada, é necessário perceber que mais do que equipar a escola, capacitar e oferecer suporte aos profissionais demanda mais urgência e possivelmente oferecerá mais retorno positivo ao ensino e à aprendizagem.

Ademais, no tópico seguinte trataremos sobre a metodologia da pesquisa. Apresentaremos além dos recursos metodológicos escolhidos, o público-alvo e as etapas de construção do estudo.

\section{Metodologia da Pesquisa}

O presente estudo utilizou os pressupostos metodológicos da pesquisa de levantamento. Conforme Gil (1999), a pesquisa de levantamento destina-se a estudos que visam coletar respostas por meio de opiniões e atitudes, e a partir de então produzir um produto que representa características de determinada população em virtude da análise de um grupo amostral.

Desse modo, as pesquisas de levantamento

[...] se caracterizam pela interrogação direta das pessoas cujo comportamento se deseja conhecer. Basicamente, procedese a solicitação de informações a um grupo significativo de pessoas acerca do problema estudado em seguida, mediante análise quantitativa, obter as conclusões correspondentes aos dados coletados (Gil, 1999).

Nesse sentido, como público-alvo desse estudo, consideraram-se as contribuições de 12 professores dos anos finais do ensino fundamental, que atuam diretamente com o componente curricular Matemática, na Secretaria Municipal de Educação de Pires Ferreira - Ceará - Brasil. Os professores participantes já tem uma expressiva bagagem no que condiz ao ensino de matemática, especialmente na educação básica. $\mathrm{O}$ público em questão participa há cerca de 6 anos de formações docentes com um grupo de professores praticamente inalterado. No que toca a estabilidade financeira/profissional, de modo geral, é possível perceber que os docentes com mais de 15 anos de experiência têm vínculo empregatício efetivo, quanto aos demais se vinculam de maneira temporária.

No ano de 2020, a realização do ciclo formativo docente promovido pela Secretaria de Educação do referido 
munícipio, sob orientação da Secretaria de Educação do Estado do Ceará (SEDUC-CE), ocorreu de forma remota e com a utilização de plataformas virtuais, com ênfase para o Google Sala de Aula, que foi a ferramenta que ofereceu suporte central para a realização da formação, que contou com 05 módulos. Em cada módulo continham: momento de discussão síncrona, material para estudo teórico, fórum de discussão, materiais complementares e atividade avaliativa ao final de cada um deles. No que compete às temáticas de formação, foram abordadas questões relacionadas ao ensino remoto emergencial, ensino híbrido, metodologias ativas de ensino e possibilidades avaliativas em contexto remoto.

Dando continuidade à pesquisa, realizou-se todo o levantamento e estudo teórico e epistemológico dos conceitos, vertentes e teorias que oferecem suporte e embasamento bibliográfico condizentes com os propósitos e contribuições pretendidas com a realização dessa pesquisa.

Posteriormente, desenvolveu-se a construção do questionário, ferramenta metodológica escolhida (Quadro 1), levantaram-se hipóteses sobre os conhecimentos prévios dos participantes e considerou-se a escala proposta por Likert (1932), com o objetivo de mensurar atitudes. Para aplicação do questionário utilizou-se o instrumento Google formulários. A aplicação/divulgação do questionário com os docentes se deu por meio das ferramentas digitais disponíveis (aplicativo de mensagens instantâneas WhatsApp).

Quadro 1 - Questionário aplicado aos professores por meio da ferramenta Google Formulários

Questionamentos diferenciados aos professores participantes do estudo.

Você já conhecia a plataforma Google Sala de Aula, antes da realização das formações?

A utilização da plataforma Google Sala de Aula favoreceu sua relação com as ferramentas digitais?

A utilização da Plataforma Google Sala de Aula contribui com sua prática profissional?

A organização estrutural da Plataforma Google Sala de Aula contribui para a realização das atividades propostas?

Fonte: Dados da pesquisa.

Posteriormente, desenvolve-se o estudo acerca das opiniões apresentadas pelos docentes na etapa anterior. Para isso construiu-se representações gráficas como síntese dos resultados obtidos na pesquisa.

Em consonância com a análise quantitativa, levantou-se aporte teórico bibliográfico condizente com as tendências numéricas observadas. A partir disso, sistematizar os resultados e conclusões percebidas com a realização desse estudo, contraponto com os objetivos pretendidos inicialmente.

\section{Resultados}

A democratização do acesso e utilização das tecnologias digitais de comunicação e informação além de ter revolucionado o campo das telecomunicações na esfera educacional, tem contribuído e facilitado questões relacionadas à formação continuada e as pesquisas científicas. Além disso, a disseminação das TDCI's se apresenta como forma de potencializar e elevar o nível da formação dos profissionais e promover a melhoria da qualidade da educação (Almeida, 2003).

Considerando o contexto pandêmico em decorrência da Covid-192, a Secretaria de Educação do Estado do Ceará realizou o ciclo de formação docente do ano letivo de 2020 de forma remota, e com suporte das ferramentas digitais disponíveis, em especial a plataforma Google Sala de Aula, onde foram disponibilizados documentos de orientação de estudo, material audiovisual, fóruns de discussão, formulários de coleta de impressão e atividades avaliativas.

A referida perspectiva formativa foi aplicada com os professores da rede municipal da cidade de Pires Ferreira, estado do Ceará - Brasil, no período de maio a outubro de 2020.

Para analisar os efeitos e impressões deixadas pela utilização dessa ferramenta no contexto da formação docente, aplicou-se com o auxílio dos formulários Google, uma pesquisa de opinião com 12 docentes do componente curricular matemática, associados à Secretaria Municipal de Educação do município supracitado. Em termos cronológicos é necessário enunciar que essa etapa se deu no mês de novembro de 2020.

Como forma de iniciar a coleta de impressões com os professores, percebeu-se a necessidade de saber se os docentes já tinham tido contato com a plataforma Google Sala de Aula antes da realização do ciclo formativo do ano letivo de 2020. A partir dessa indagação obteve-se como resposta que mais da metade dos docentes participantes não conheciam a ferramenta digital (Figura 1).

Figura 1 - Conhecimento dos docentes em relação à plataforma Google Sala de Aula anteriormente ao Ciclo formativo 2020

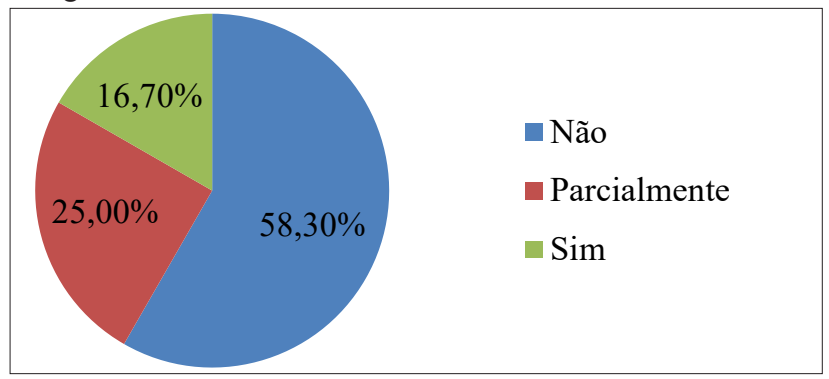

Fonte: Dados da pesquisa.

No que tange ao uso das tecnologias, a formação do professor ainda têm necessidade de aperfeiçoamento, pois os docentes desconhecem o meio tecnológico e suas ferramentas, ou por assim dizer, conhecem apenas em teoria. Essa análise encaixa-se nos pressupostos teóricos discutidos anteriormente,

2 Síndrome respiratória aguda grave, que emergiu no final de 2019 em Wuhan, Provincia de Hubei, China, e rapidamente se disseminou por todos os continentes (Iser et al., 2020). 
no exposto sobre a urgência de desenvolvimento de formações docentes com apoio de novas vertentes teórico-metodológicas.

Para Tourmen (2014) a análise da prática docente no viés da Didática Profissional compreende que a formação pode se constituir a partir da análise do trabalho do professor ou durante a formação se promover a análise. Desse modo, há de se pensar que nesse caso específico, a formação do professor deve ser orientada a partir da análise das necessidades do docente, ou seja, das deficiências em sua prática.

Diante disso, percebe-se que a formação pedagógica para o uso das tecnologias no ensino não são responsabilidade apenas da formação continuada, mas devem partir da inicial. Para Cysneiros (2000)

[...] o ideal é que o professor aprenda a lidar com as TI [Tecnologias da Informação] durante sua formação regular, em disciplinas mais ou menos com os nomes de "Tecnologia Educacional" ou "Tecnologias da Informação na Educação" e de modo mais detalhado nas didáticas de conteúdos específicos.

No trecho anterior é explicitada a necessidade de maior atenção à inserção e/ou efetivação, ou ainda, emergência das didáticas específicas de ciências (no caso especial da Matemática, nesse âmbito), nos cursos de formação docente, tendo em vista seu grau de importância e necessidade.

Posteriormente questionou-se aos professores se eles acreditavam que a utilização da plataforma digital Google Sala de Aula no ciclo de formação continuada favoreceu e estimulou a relação dos mesmos com as ferramentas digitais. Percebeu-se que todos os participantes da pesquisa acreditam que sim, uma vez que desenvolveram na prática habilidades e conhecimentos antes não utilizados.

Considerando a opinião dos professores e as implicações teóricas já trazidas anteriormente nesse estudo no que condiz a inserção das Tecnologias digitais de comunicação e informação na área educacional, é válido ressaltar o pensamento de André (2004), quando defende que

Urge, pois, inserir as diversas tecnologias da informação e das comunicações no desenvolvimento dos cursos de formação de professores, preparando-os para a finalidade mais nobre da educação escolar: a gestão e a definição de referências éticas, científicas e estéticas para a troca e negociação de sentido, que acontece especialmente na interação e no trabalho escolar coletivo. Gerir e referir o sentido será o mais importante e o professor precisará aprender a fazê-lo em ambientes reais e virtuais.

O autor ressalta a importância de inserir os docentes dentro do contexto das TDCI's para que assim ele possa compreender os diferentes aspectos dos ambientes educacionais virtuais, uma vez que se espera que a vivência nos ambientes reais se efetive. Colocar o professor em cenário de formação é tornálo também aluno, e dessa maneira, experimentar ambas as ópticas da relação com a aprendizagem, ensinar e aprender.

Nesse sentido, retorna-se aos preceitos da Didática Profissional, assim como coloca Pastré quando defendem a necessidade do contato do profissional com o novo, ambientes e situações de desafios e reflexão.

Em conseguinte, questionou-se a opinião dos docentes sobre se a utilização de ferramentas digitais no contexto da formação continuada promoveu aprendizagens. Todos responderam de forma afirmativa, confirmando as discussões anteriores sobre a necessidade de um novo olhar para a relação de utilização de tecnologia no ensino e os direcionamentos formativos aos profissionais.

A DP por sua vez, corrobora com a situação encontrada, dado que nesse caso, as experiências vividas e as atividades realizadas nessas circunstâncias promovem o desenvolvimento de recursos (aprendizagens/conhecimento). Esse pensando é descrito por Tourmen (2014) quanto afirma que a formação proposta pela Didática Profissional se diferencia dos modelos tradicionais por considerar a experiência do profissional, que compreende variadas dimensões, entre elas as situações vividas, a atividade em situação e os recursos desenvolvidos, em detrimento das análises sobre a prática.

De maneira semelhante ao questionamento anterior, perguntou-se aos professores participantes da pesquisa se eles acreditam que a utilização do Google Sala de Aula contribuiu de alguma maneira com sua prática profissional. Com as respostas referentes a essa indagação (Figura 2), percebeu-se que praticamente em sua totalidade, os docentes responderam de forma afirmativa. Apenas um docente mostrou-se de maneira imparcial, ou seja, não discorda das contribuições advindas da utilização dessas plataformas digitais, no entanto, não pôde perceber seus benefícios de maneira clara.

Figura 2 - A existência de contribuições da Plataforma Google Sala para a prática profissional, na concepção dos docentes

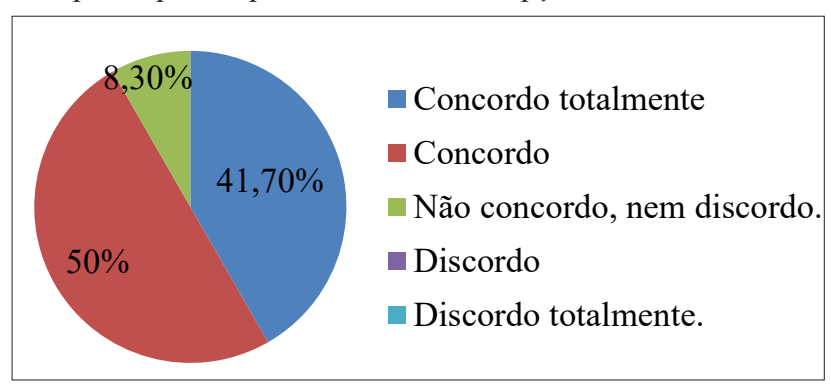

Fonte: Dados da pesquisa.

É importante destacar a capacidade dos docentes em reconhecerem a necessidade de adequar-se as ferramentas digitais e as aprendizagens advindas de sua utilização. Assim como afirmam Almeida \& Silva (2011), quando colocam que é necessário conviver e aprender com as tecnologias, enxergando que elas são meio de inteiração, participação, registro e partilha de informação, e consequentemente de geração de conhecimento.

Na concepção da DP a relação do professor com o lócus de trabalho é essencial. Nesse caso, com o ambiente virtual não é diferente, uma vez que se percebe a aprendizagem advinda da utilização, da exposição do profissional as condições do espaço, considerando, especialmente nesse exemplo, as realidades digitais. 
A partir do momento em que houver a compreensão de que a utilização das TDCI's no ensino promove a impulsão de inovações pedagógicas, passará a existir a criação de uma rede de construção de significados, acreditando-se em uma aprendizagem colaborativa e na expansão do espaço e do tempo escolar. Como consequência disso, a desmistificação da ideia de uma tecnologia isolada da sala de aula.

Com relação à estrutura da plataforma digital Google Sala de Aula, questionou-se aos professores se eles consideram que a organização e apresentação estrutural da ferramenta facilita o acesso aos materiais e a realização das atividades propostas. Em uma análise percentual das respostas, é possível perceber que em sua maioria, os docentes acreditam que sim (Figura 3).

Figura 3 - Opinião dos docentes em relação às contribuições da organização estrutural da ferramenta digital Google Sala de Aula para as realizações das tarefas propostas

\begin{tabular}{|l|l|}
\hline $8,30 \%$ & Concordo totalmente \\
$33,30 \%$ & $\begin{array}{l}\text { } \\
\text { }\end{array}$ \\
& Concordo \\
$58,30 \%$ & Não concordo, nem discordo. \\
& Discordo \\
& Discordo totalmente.
\end{tabular}

Fonte: Dados da pesquisa.

A organização estrutural das plataformas digitais ainda é um obstáculo a ser vencido pelos docentes, em especial para aqueles que estão em processo de adaptação. Ramos et.al (2001) acredita que dentre outros fatores que oferecem objeção para o uso das TDIC's na educação, destacam-se: problemas técnicos com os equipamentos, organização de espaços e horários em ambiente escolar e a apresentação/ técnica de manuseio das ferramentas.

Entendendo o ambiente virtual como sendo o ambiente profissional do docente (nessa realidade), relaciona-se esses entraves ao que disse Mayen (2012), quando apresenta o conceito de ambiente (situação profissional) como aquela em que o profissional ou futuro profissional estão em contato, o que necessitam fazer e o que tem que gerenciar. Assim, mesmo em meio digital, a forma como o profissional docente lida com as situações, fala muito sobre suas experiências, formação e orienta a construção de novas posturas frente à parte ativa do campo profissional.

\section{Considerações Finais}

Nos tópicos anteriores discutiu-se sobre a formação docente, em que mesmo reconhecendo a evolução e as melhorias na área, é notória a necessidade de constantes pesquisas e estudos que venham a contribuir com a inovação do ensino e com o enriquecimento do profissional da educação em si, uma vez que se compreende a relação de interdependência de ambas as características.

Nesse sentido, é indispensável destacar o importante papel do estudo acerca da Didática Profissional, que vem fomentar as concepções relacionadas à aprendizagem do profissional, em especial o docente, e a maneira como essa ocorre, no dinamismo e desenvolvimento de suas atividades laborais, ainda percebendo os impactos e reforços produzidos pelas condições socioambientais.

De maneira mais específica, pôde-se destacar a necessidade de fortalecimento de utilização das ferramentas digitais no contexto educacional. Mais que isso, o emprego consciente e eficaz dessas ferramentas, que se bem empregadas e com objetivos claros, podem favorecer estímulo e contribuir com o desenvolvimento de aprendizagens.

Estimulado pelos resultados obtidos a partir da aplicação da ferramenta metodológica escolhida, ou seja, da coleta de impressões com os docentes participantes desse estudo, e em consonância com os pressupostos teóricos supracitados, constata-se o real desconhecimento dos profissionais no que condiz a existência de ferramentas e plataformas digitais desenvolvidas e/ou adaptadas para oferecer suporte educacional.

Convém ainda destacar que no que compete à formação docente, é notório que além de apresentação e aporte teórico relacionado ao uso de tecnologia no ensino, a aplicação dessas ferramentas deve ser vivenciada substancialmente, compreendendo ainda que o docente precisa sentir-se discente nesse trato, para compreender em primeiro lugar os anseios e necessidades de seus alunos, assim como configura a DP quanto apresenta a necessidade de uma formação originada/ desenvolvida a partir da análise da prática docente.

Perspectiva-se que isso impulsione os docentes a construírem uma relação mais sólida e madura no que condiz ao uso das tecnologias no ensino e que essa ação culmine em promoção de aprendizagens substanciais para o profissional.

Pretendeu-se com esse estudo verificar as impressões dos professores quanto ao uso do Google Sala de Aula como ferramenta digital de suporte às formações pedagógicas. Nesse sentido, perceberam-se respostas positivas, pois ao lidar com esses recursos e dispositivos, o profissional desenvolve ou aperfeiçoa competências e habilidades nunca antes utilizadas e/ou consolida aquelas já internalizadas.

Essa pesquisa limitou-se a analisar a relação do professor quanto participante de um processo formativo, a utilização de ferramentas digitais como suporte e de que forma a Didática Profissional poderia oferecer subsídios de reflexão e aprimoramento dessa formação. Diante do exposto, compreende-se que são necessários melhoramentos no que tange a organização e disposição dos recursos/materiais para estudo e da concepção de formação que promova a vivência ativa daquilo que se apresenta teoricamente. Este último, se adequa ao caso desse estudo, pois os docentes mesmo não conhecendo previamente à plataforma utilizada, ao longo do percurso adquiram novas habilidades e/ou efetivaram competências.

Ainda assim, surge à necessidade de ser levantada uma nova problemática relacionada à aplicação dos aspectos 
envolvidos nesse processo, ou seja, como se dará e quais contribuições suscitarão a construção e desenvolvimento de sessões didáticas por esses profissionais tendo como públicoalvo seus respectivos alunos.

Em suma, apreendeu-se que a tecnologia ainda é usava de maneira irrisória em sala de aula, que os docentes em atuação tem um conhecimento apenas superficial acerca das possibilidades que o uso dessas ferramentas tem a oferecer e que a formação do professor anseia dela inserção desses mecanismos, que privilegiem a utilização prática e envolvente dos mesmos.

\section{Referências}

Almeida, M. E. B. \& Silva, M. G. M. (2011). Rev. E-curriculum, 7 (1).

Almeida, M. E. B. (2003). Tecnologia e Educação à distância: abordagens e contribuições dos ambientes digitais e interativos de aprendizagem. São Paulo: PUC-SP.

Alves, F. R. V. \& Catarino, P. M. M. C. (2019). Situação Didática Profissional: um exemplo de aplicação da Didática Profissional para a pesquisa objetivando a atividade do professor de Matemática no Brasil. Indagatio Didactica, 11 (1).

Alves, F. R. V. \& Dias, M. A. (2017). Formação de professores de matemática: um contributo da engenharia didática (ED). Revemat, 12 (2), 192-209.

Alves, F. R. V. \& Jucá, S. C. C. (2019). Trabalho e competência do professor de matemática: um ponto de vista a partir da didática profissional. Educa, 6, 103-23.

Alves, F. R. V. (2020). A Didática Profissional (DP): implicações para a formação do professor e o ensino. Rev. Iberoam. Estud. Educ., 15 (4), 1903-18. doi: https://doi.org/10.21723/riaee. v15i4.13377.

Alves, F. R. V. (2020). Didática Profissional (DP) e a didática das ciências e matemática (DCEM): uma perspectiva de complementaridade e implicações para o trabalho do professor. Investig. Ensino Ciênc. doi: http://dx.doi. org/10.22600/1518-8795.ienci2020v25n3p397

André, M. (2004). Uma pesquisa com os professores para avaliar a formação de professores.

Araújo, J. \& Araújo, K. (2013). EaD em Tela: docência, ensino e ferramentas digitais. Campinas: Pontes.

Barreto, R. G. (2004). Tecnologia e Educação: trabalho e formação docente. Educ. Soc., 25 (89), 1181-201.

Cysneiros, P. G. (2000). Novas tecnologias no cotidiano da escola. Anais da XXIII Reunião Anual da ANPED, Caxambu,
MG: ANPEd.

Gil, A. C. (1999). Métodos e técnicas de pesquisa social. São Paulo: Atlas

Godino, J. D.; Batanero, C. \& Font, V. (2007). The onto-semiotic approach to research in mathematics education. ZDM. Int. J. Mathem. Educ., 39 (1/2), 127-35.

Iser, B. P. M.; Silva, I.; Raymundo, V. T.; Poleto, M. B.; Schueltertrevisol, F. \& Bobinski, F. (2020). Definição de caso suspeito da COVID-19: uma revisão narrativa dos sinais e sintomas mais frequentes entre os casos confirmados. Santa Catarina. Epidemiol. Serv. Saude, 29(3) e2020233.

Lévy, P. (1998). A máquina universo: criação, cognição e cultura informática. Porto Alegre: Artmed.

Likert, R. (1932). A technique for the measurement of attitudes.

Mendes, H. L. S.; Alves, F. R. V. \& Santos, M. J. C. (2020). A didática profissional: ambiente de formação e ambiente de trabalho. Revemat, 15, 1-18.

Morin, E. (2003). Os setes saberes necessários à educação do futuro. São Paulo: Cortez.

NÓVOA, A. (1996). Formação de professores e profissão docente. Lisboa: Dom Quixote,

Pereira, A. M. (2011). Tecnologia x Educação. Rio de Janeiro: Universidade Candido Mendes.

Perrenoud, P. (1993). Práticas pedagógicas, profissão docente e formação: perspectivas sociológicas. Lisboa: Publicações Dom Quixote.

Quadros-Flores, P. (2016). A Identidade Profissional Docente e as TIC: Estudos de Boas Práticas no $1^{\circ}$ Ciclo do Ensino Básico na região do Porto. Berlin: Novas Edições Acadêmicas.

Ramos, J.; Carmo, M.; Fernandes, I.; Leask, M. Y. \& Younie, S. (2001). A Escola que aprende: um estudo múltiplo de casos no âmbito da utilização educativa das TIC em escolas europeias. O caso português. Rev. Inov. Novas Tecnol. Educ., 14(3) 97-118.

Sacristán, J. G. \& Gómes, A. I. P. (2000). Compreender e transformar o ensino. Porto Alegre: Artmed.

Sousa, R. C.; Alves, F. R. V. \& Fontenele, F. C. F. (2020). Engenharia Didática de Formação (EDF): uma proposta de situação didática do ENEM com o uso do software GeoGebra para professores de matemática no Brasil. Rev. Iberoam. Tecnol. Educ. Educ. Tecnol, (26), 90-9. doi: 10.24215/18509959.26.e10.

Souza, R. P.; Moita, F. M. C. S. \& Carvalho, A. B. G. (2011). Tecnologias Digitais na Educação. Campina Grande: EDUEPB.

Tourmen, C. (2014). Usages de la didactique professionnelle en formation: principes et évolutions. Savoirs, 36 (3), 9. 